\title{
Controlled Tuning of the Size of Ag-hydrosol Nanoparticles by Non- Stabilized THF and Detection of Peroxides in THF
}

Ivana Šloufová $^{1 *}$, Miroslav Šlouf ${ }^{2}$, Blanka Vlčková ${ }^{1}$, Veronika Gajdošováa $^{1,2}$, Jiří Zedník $^{1}$, Jiří Vohlídal $^{1 *}$

${ }^{1}$ Charles University, Faculty of Science, Department of Physical and Macromolecular Chemistry, Hlavova 2030, 12840 Prague 2, Czech Republic

${ }^{2}$ Institute of Macromolecular Chemistry, Czech Academy of Sciences, Heyrovskeho nam. 2, 16206 Prague 6, Czech Republic

*E-mail for Ivana Šloufová: sloufovi@natur.cuni.cz, Jiř́ Vohlídal:jiri.vohlidal@natur.cuni.cz 


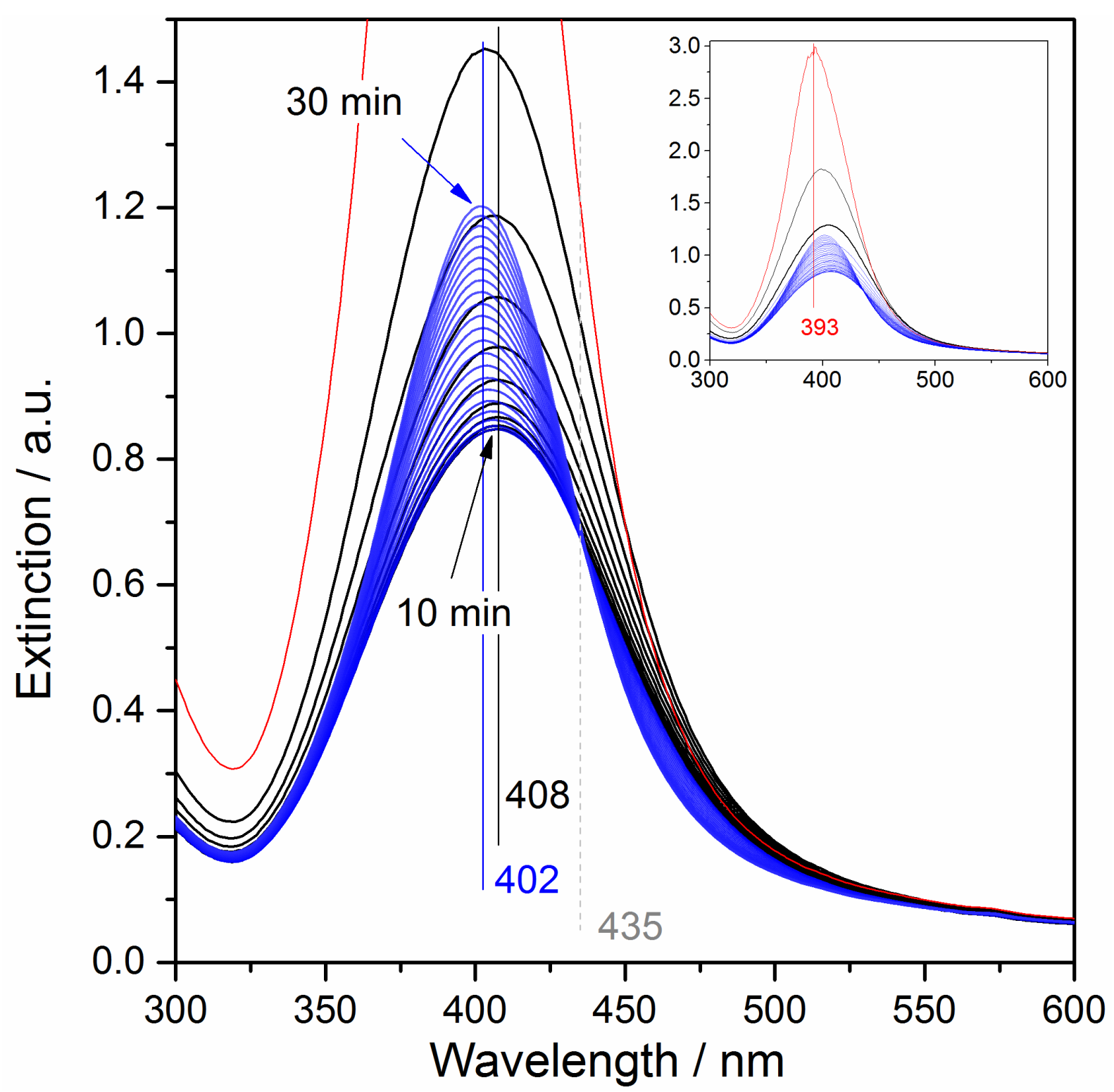

Figure $\mathbf{S 1}$ - Surface plasmon extinction spectra of the system with $2 \mu \mathrm{L}$ of THF measured in the time interval $0-30 \mathrm{~min}$. 

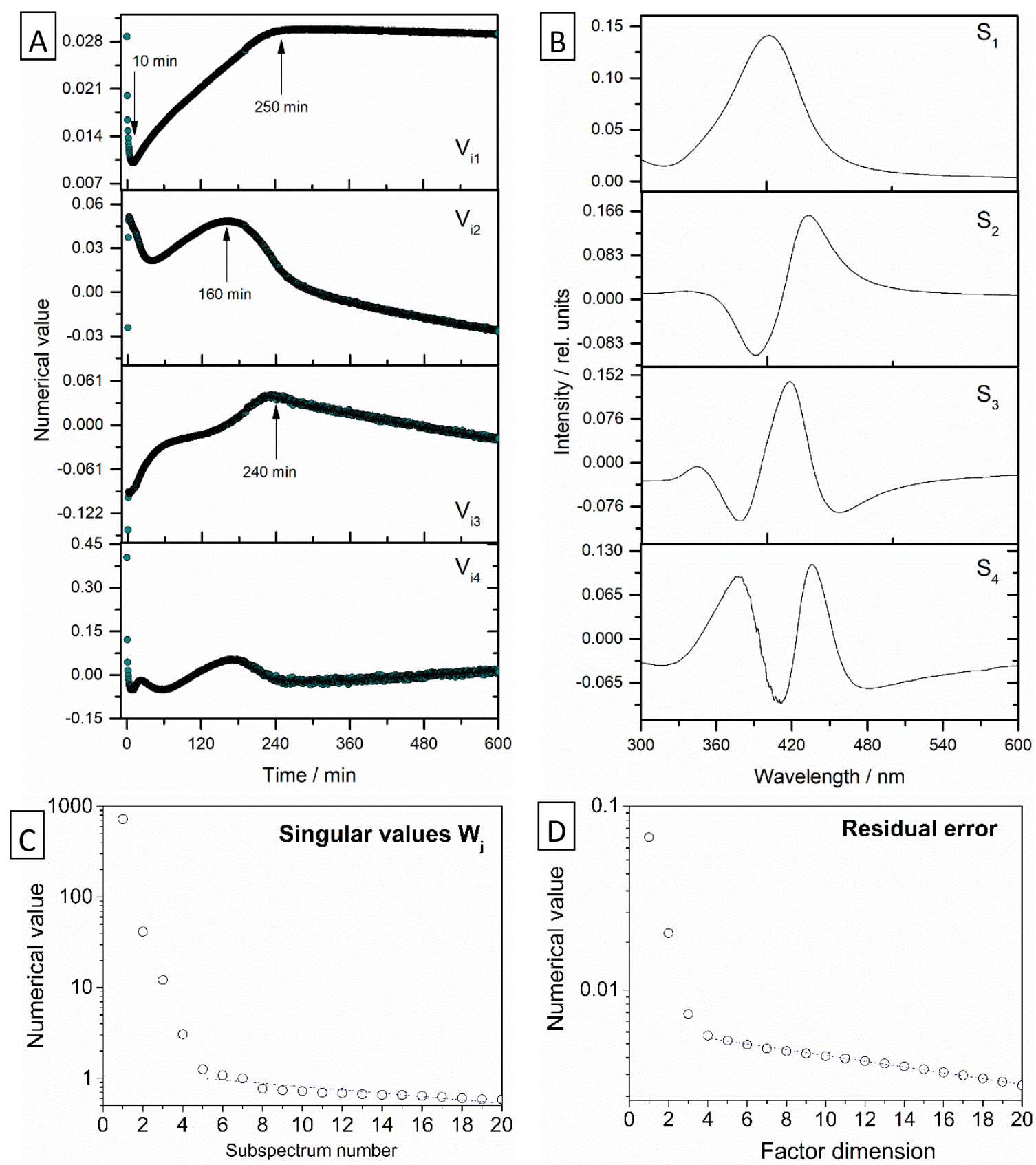

Figure S2 - Factor analysis of the set of SPE spectra of system II ( $3 \mathrm{~mL}$ of Ag NPs $+3 \mu \mathrm{L}$ of THF-HPO) measured as a function of time: (A) $1^{\text {st }}$ to $4^{\text {th }}$ subspectrum $\left(S_{1}-S_{4}\right)$, (B) virial coefficients $V_{i j}(j=1$ to 4$)$ as a function of time, (C) singular values $W$ as a function of the subspectrum number, (D) residual error as a function of factor dimension. 


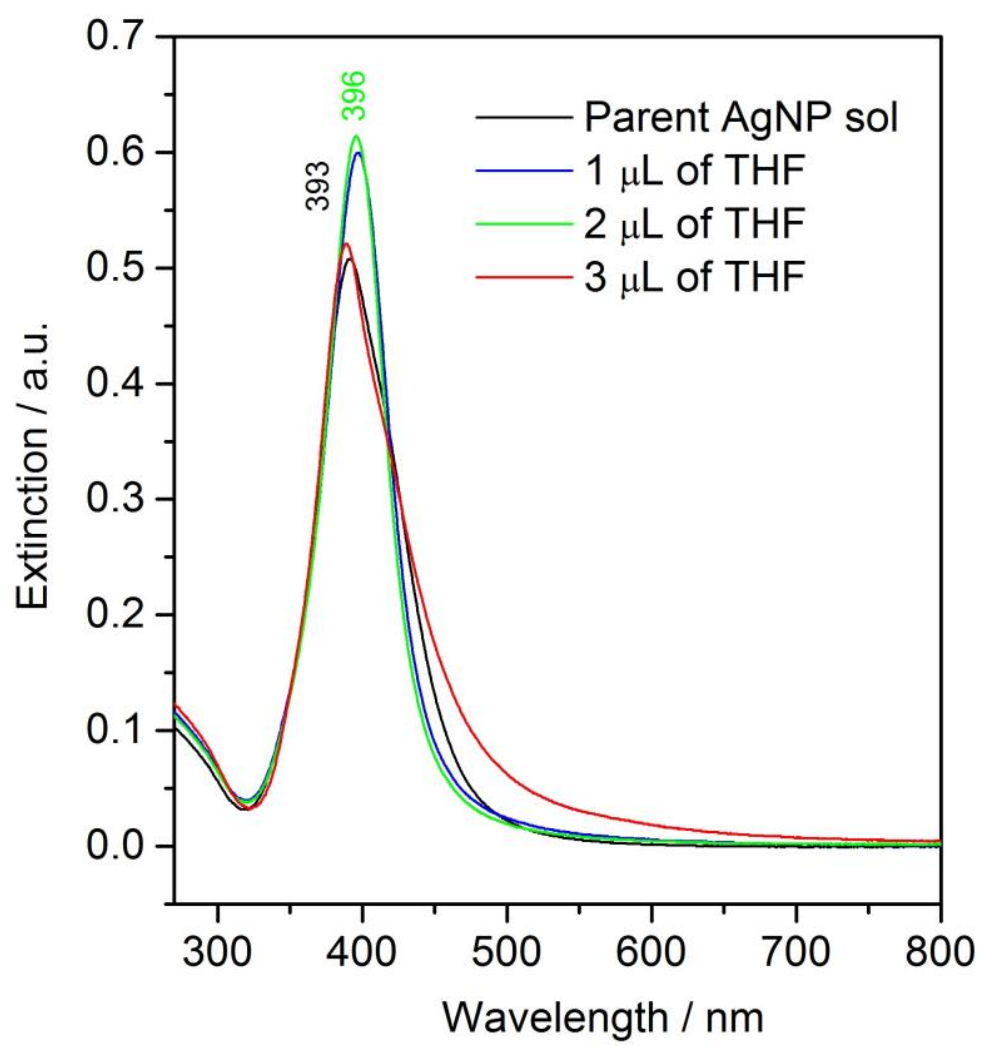

Figure S3 - UV/vis spectra of the parent Ag NP sol and the ripe sols with added 1 to $3 \mu \mathrm{L}$ of aged THF measured two days after preparation $(0.2 \mathrm{~cm}$ cuvette). 


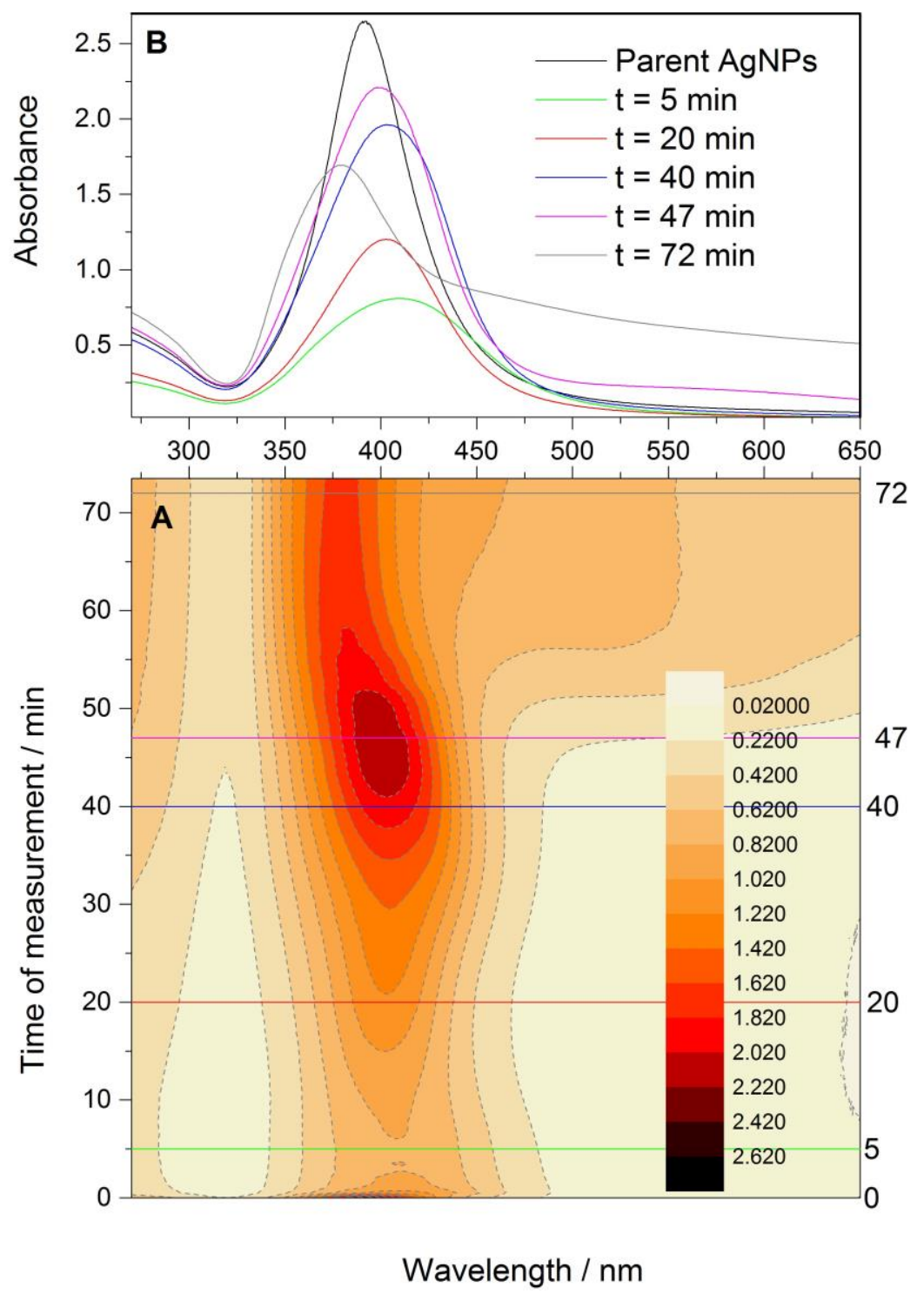

Figure S4 A - Contour profile plot showing time series of surface plasmon extinction spectra collected during dissolution and recovery of Ag NPs (60-days old). B - Selected SPE spectra from the contour profile. 


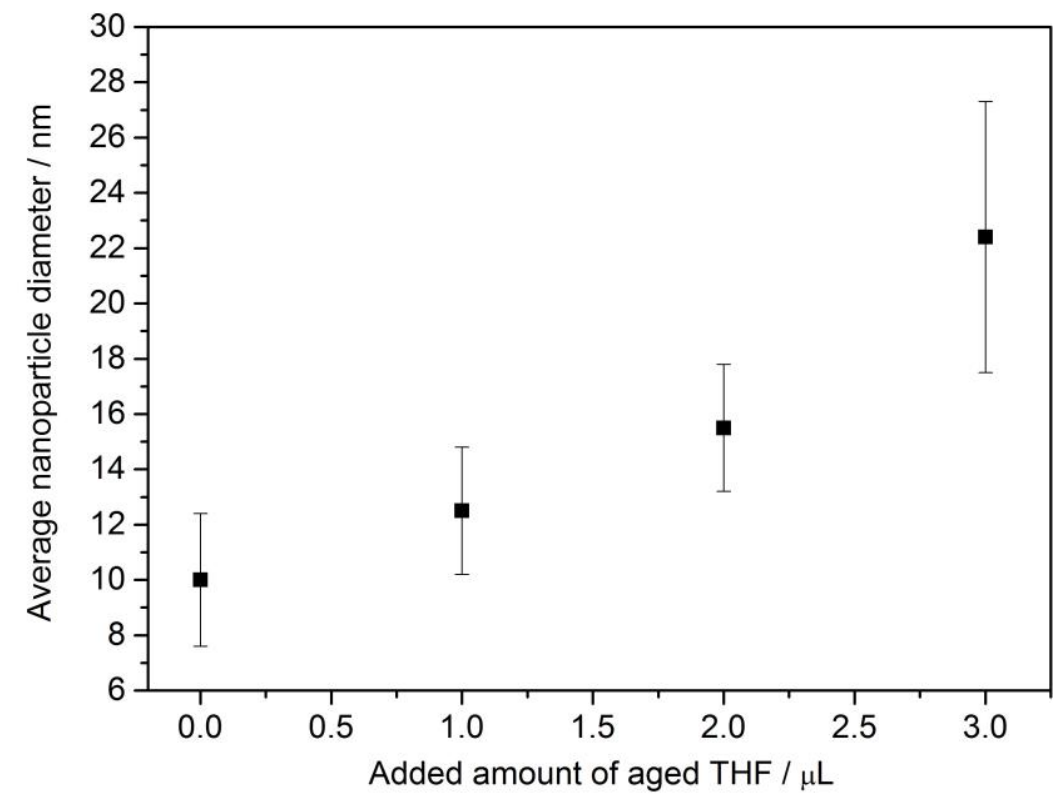

Figure S5 - The dependence of average particle size on the amount of added aged THF.

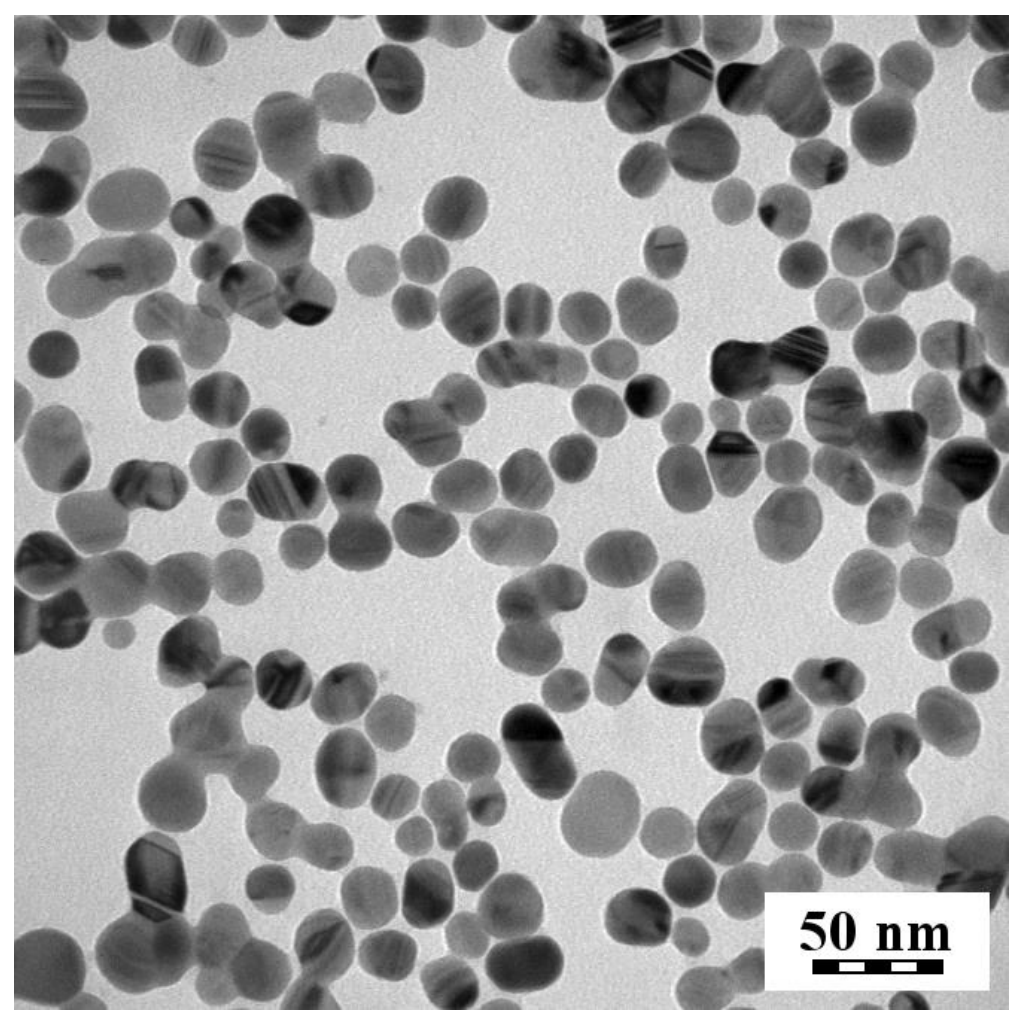

Figure S6 - TEM image of Ag NPs obtained after termination of plasmon recovery of the system prepared by addition $3 \mu \mathrm{L}$ of aged THF to $3 \mathrm{~mL}$ of parent Ag NPs. 


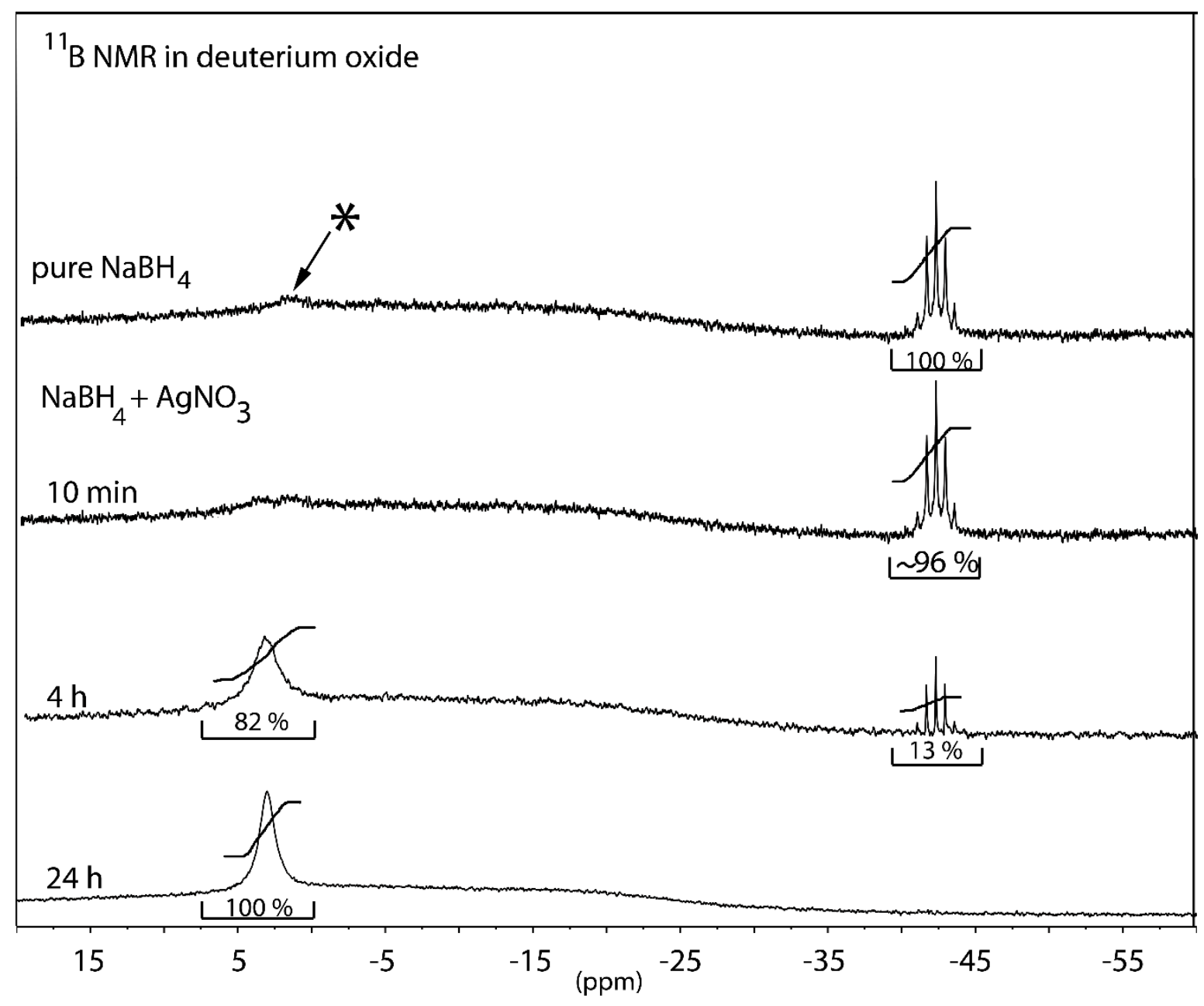

Figure S7 - ${ }^{11} \mathrm{~B}-\mathrm{NMR}\left(121.31 \mathrm{MHz} \mathrm{H} \mathrm{O}_{2} \mathrm{O}-\mathrm{ppm}\right)$ spectra of of the $\mathrm{NaBH}_{4}$ solution $\left(1,2 \cdot 10^{-2} \mathrm{M}\right)$ in the presence of $\mathrm{AgNO}_{3}\left(2,21 \cdot 10^{-2} \mathrm{M}\right)$. NMR signal marked by asterisk is the signal of borate anion. 


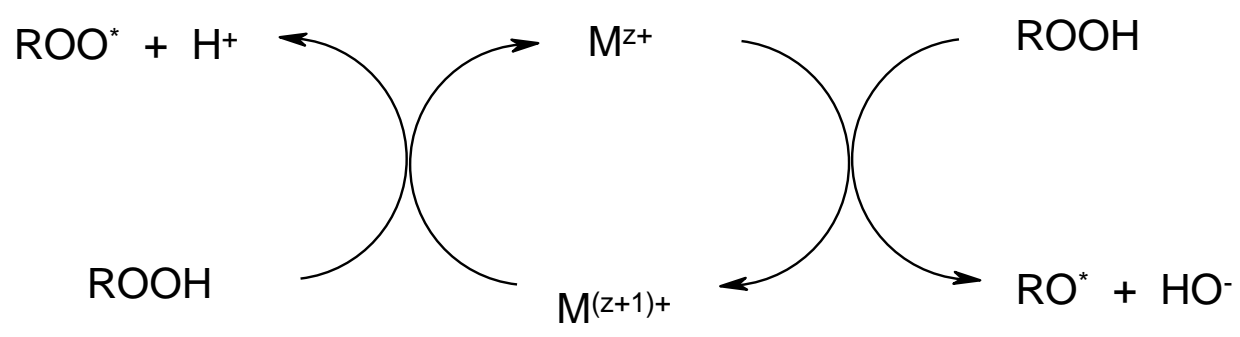

Scheme S1 - Catalytic cycle of organic peroxides and metal ions. 